\title{
Brief intervention addressing excessive cannabis use in young people consulting their GP: a pilot study
}

Dagmar M Haller, Anne Meynard, Danièle Lefebvre, André Tylee, Françoise Narring and Barbara Broers

\begin{abstract}
Background

When excessive cannabis consumption occurs in adolescence, the adverse consequences extend into adulthood. Interventions by GPs are effective in preventing harm associated with alcohol use. Similar interventions have potential in addressing cannabis use.
\end{abstract}

Aim

To develop and pilot test a brief intervention targeting excessive cannabis use (defined as $\geq 1 \times /$ week) in young people in primary care.

Design of the study

Pilot intervention trial.

Setting

Seven family practices in Switzerland.

\section{Method}

The team collaborated with GPs and young people to develop the intervention. Seven GPs piloted its use in their consultations. Patients aged 15 to 24 years consulting for any health problem were recruited before the consultation. Cannabis use, other substance use, and their psychosocial correlates were assessed with a short confidential questionnaire administered before the consultation and 1 month later. GPs, staff, and patients were asked to comment on the study and its feasibility.

Results

Of 81 young people invited to participate, $78(70 \%$ female) agreed (participation rate: $96 \%)$. One in seven $(13.2 \%, 95 \%$ confidence interval $=7.5 \%$ to $18.9 \%)$ used cannabis at least once a week. Data at 1 month were available for $42 \%$ who had provided email contact details and $91 \%$ of those who had provided their mobile phone number (63\% overall). In most cases, the intervention lasted no more than 5 minutes. Comments from participants added favourable data towards the feasibility of the study.

\section{Conclusion}

This pilot study provides a solid base on which to build a randomised trial of a brief intervention addressing cannabis use in young people consulting in family practice.

\section{Keywords}

adolescent; cannabis; family practice; prevention and control; substance-related disorders.

\section{INTRODUCTION}

The adverse short- and long-term outcomes of excessive cannabis use are well documented. ${ }^{1}$ When excessive cannabis use occurs at a vulnerable age such as adolescence, the physical, psychological and developmental consequences extend into adulthood. ${ }^{2}$ Young people who use cannabis regularly have lower educational achievements, engage in more healthcompromising behaviours, suffer more accidental injuries and respiratory disorders, and have higher rates of mental disorder and cognitive impairment. ${ }^{3-7}$ Regular use of cannabis during adolescence is associated with psychosocial maladjustment in later life, suggesting that it interferes with the developmental process of adolescence. ${ }^{2,8}$ Weekly or more-frequent cannabis use in adolescence is related to a fivefold increase in the risk of dependence in adulthood. ${ }^{9}$

The prevalence of regular cannabis use is high

DM Haller, PhD, MD, academic GP, Department of Community Medicine \& Primary Care, Geneva University Hospitals and University of Geneva Switzerland, and honorary fellow, Department of General Practice, The University of Melbourne, Australia. A Meynard; MD, primary care physician; F Narring, MSc, MD, primary care physician, head, Adolescent \& Young Adult Program, Department of Child and Adolescent Medicine, Geneva University Hospitals, Switzerland. D Lefebvre, MD, GP, Versoix, Switzerland. A Tylee, MD, professor of primary care mental health, Health Services \& Population Research Department, Institute of Psychiatry, London. B Broers, MSc, MD, internist and addiction specialist, Department of Community Medicine \& Primary Care, Geneva University Hospitals and University of Geneva, Switzerland.

Address for correspondence

Dr Dagmar M Haller, Division of Primary Care, Department of Community Medicine \& Primary Care Geneva University Hospitals, 24 rue Micheli-du-Crest 1211 Geneve 14. Switzerland.

E-mail: dagmar.haller-hester@hcuge.ch

Submitted: 10 April 2008; Editors response: 10 June 2008; final acceptance: 9 July 2008.

() British Journal of General Practice 2009; 59: 166-172.

DOI: 10.3399/bjgp09X419529 
among young people in Switzerland. In the Swiss Multicenter Adolescent Survey on Health (SMASH), which included over 7500 young people aged 16 to 20 years, $13 \%$ of boys and $4 \%$ of girls used cannabis daily, and $28 \%$ of boys and $14 \%$ of girls had used cannabis three or more times in the past month. ${ }^{10}$ The results of the international Health Behaviour in SchoolAged Children (HBSC) study placed Switzerland before Canada, the US, and the UK as the country with the highest prevalence in the world of regular cannabis users ( $\geq 40$ times a year) by the age of 15 years (9.4\%). ${ }^{11,12}$ Although in 2006 the HBSC survey showed a stabilised trend, the prevalence of use remains high, with one in three boys and one in four girls having used cannabis at least once by the age of 15 years. ${ }^{13}$

\section{The role of GPs in addressing excessive cannabis use in young people}

To date, prevention efforts have focused on primary prevention at a population level (media campaigns, school, family, and community programmes) or treatments of dependent users in specialised settings. ${ }^{14-17}$ GPs can add to these efforts by offering an early individual approach addressing excessive use in young people who do not fit the criteria for a diagnosis of dependence. Evidence favours brief interventions by GPs to prevent harm associated with tobacco or alcohol use. ${ }^{18-23}$ Similar interventions have potential in addressing excessive cannabis use..$^{24}$

Adolescent health care is typically ambulatory care; $70-90 \%$ of young people are in contact with GPs at least once a year. ${ }^{25-27}$ It has been shown that in Switzerland this proportion is the same for young cannabis users. ${ }^{28}$ These consultations offer an ideal point of contact between young people and health professionals. ${ }^{29,30}$ A brief intervention was successful in reducing cannabis use in a college setting. ${ }^{31}$ Researchers in a pilot test of an intervention addressing substance use in ambulatory care met unexpected difficulties in recruiting patients for their study. ${ }^{32}$ There is a gap in the available evidence on the benefits of brief interventions by GPs to address excessive cannabis use in young people. . $1533^{3}$ More information is also needed on the feasibility of trialling such an intervention in family practice.

The aim of this project was therefore to develop a brief intervention targeting excessive cannabis use in young people aged 15 to 24 years consulting GPs, and to pilot its use in family practices. It was also to pre-test the methods of a cluster randomised trial evaluating the effectiveness of this intervention.

\section{METHOD}

Development of the intervention and of the procedure for the study

Twenty-six GPs from the Geneva area (GPs, internists,

\section{How this fits in}

The short- and long-term adverse consequences of excessive cannabis use are now well known. Despite the high prevalence of cannabis use among young people, cannabis use is rarely discussed in GP consultations. A brief intervention has potential in reducing cannabis use, and other substance use, in young people consulting in family practice.

and paediatricians, known to the research team and purposively selected for their potential interest in contributing to a project involving youth) were sent an invitation to contribute to an advisory group for the study. A member of the research team phoned them a week later to assess their interest in participating, and as most responded positively, the first 10 were selected for participation in the advisory group. They collaborated in three 2-hour sessions with members of the research team to define the contents of the intervention and the procedure for its trial in their practices. They revised this procedure following feedback from an advisory group of five young people aged 15 to 18 years recruited through members of the research team.

The general model for the intervention was that of a brief intervention using a motivational interviewing style and a guide known as the 5As (Box 1). ${ }^{34,35}$

The use of adolescent actors has been shown to be beneficial to GPs training to communicate with young people. ${ }^{36}$ Four adolescent actors were therefore trained to play the role of patients attending a GP, and to provide individualised feedback to the doctors. In a 2hour session in the month prior to patient recruitment, the doctors tested both their ability to provide the intervention and the entire study procedure with these actors. Final refinements were made to the procedure following these training sessions.

\section{Piloting the intervention in the practices}

Participants. Seven of the 10 members of the advisory group volunteered to pilot the intervention and study procedure in their practices. Of the three GPs who left the study at this stage, one indicated that she no longer had enough time to participate and two explained that they currently saw only one or two young people aged 15 to 24 years a week in their practice, thus making it difficult for them to recruit patients into the study.

\section{Box 1. Main components of 5As} intervention. ${ }^{34}$

Ask about use

Advise to stop

Assess willingness to stop

Assist in stopping attempt

Arrange follow-up 
Patient recruitment took place over 2 months (April to May 2007). In all but one practice, consecutive young people aged 15 to 24 years attending the practices for any health problem were eligible for the trial. In one practice in which many young people in this age group were seen, the GP chose to include only the first eligible patient in the morning and the first in the afternoon. Patient exclusion criteria were: acute illness requiring immediate attention, severe mental disorder requiring treatment in a specialised setting (psychosis or suicidal intentions), drug or alcohol abuse requiring moreimmediate attention (for example, alcohol abuse and recent court ruling regarding drunk driving), or previous treatment for cannabis or alcohol dependence.

The choice of the age group was based on several considerations. Throughout a continuum starting in early adolescence and ending in adulthood, individuals share a similar burden of health problems related to psychosocial issues. ${ }^{37}$ The World Health Organization's definition of young people encompasses those aged 10 to 24 years. ${ }^{38}$ Although initiation of cannabis use begins earlier, the percentage of young people who may benefit from an intervention is lower in those younger than 15 years. Also, young people have repeatedly identified confidentiality as a key priority when accessing health care..$^{39}$ Thus, it was important that young people could consent to participation without asking their parents. ${ }^{40}$ As previous experience has shown, young people from the age of 15 years have the ability to consent to participation in low-risk research on their own. ${ }^{40,41}$

Procedure. Prior to the consultation, eligible patients were invited to complete a confidential survey with questions evaluating substance use and sociodemographic and psychosocial variables. This survey was based on instruments used in the Swiss Multicenter Adolescent Survey on Health and on the DEP-ADO (an instrument to measure substance use in adolescence). ${ }^{10,42}$ It took approximately 10 minutes to complete and was anonymous. ${ }^{43}$ This was important as the young people advising the study underlined that they would be less likely to respond honestly to a questionnaire if it were to be used by the doctor in the consultation. Therefore this pre-consultation questionnaire was not available for the doctors to help them identify at-risk consumers. Participants provided written consent and completed the questionnaire in the waiting room. They were asked to provide either a contact mobile phone number or an email address for follow-up 1 month following the consultation. A code was used to link baseline to follow-up information. Participants then had their medical consultation in which all patients were first offered usual care for the problem for which they had come. The doctors then introduced the topic of substance use and the first step of the brief intervention (identification of at-risk use). All participants were therefore exposed to the initial elements of the intervention. If the doctor identified a need, the full intervention was delivered. For each patient, the doctors recorded how many steps of the brief intervention they completed and how long the intervention lasted.

As this was a pilot study, the main outcome measures were related to feasibility and were: recruitment and participation rate, mean duration of the intervention, and follow-up rate. Patients', doctors', and practice staff's comments on the study were also noted. These comments were collected during the follow-up interview for patients, in individual interviews at the end of the study for the practice staff, and in a group session with the GPs. In addition, baseline and follow-up levels of excessive substance use (measured by point prevalence of self-reported excessive cannabis use $[\geq 1 \times /$ week $]$ and/or self-reported excessive alcohol use [ $\geq 1$ episode of binge drinking] in the past 30 days, and daily tobacco use) were used to assess the proportion of young people who could benefit from the intervention and the potential for effectiveness of this intervention. (In Switzerland, young people can legally purchase wine and beer from the age of 16 years, and spirits from the age of 18 years).

Data were analysed using Stata (version 9.1). Outcomes were computed using frequencies, and 95\% confidence intervals (Cls) were adjusted for clustering within practices.

\section{RESULTS}

The main results are summarised in Figure 1. Of 81 young people who were eligible to participate, 78 agreed (one was excluded, two declined), and 76 completed the baseline questionnaire. Most were female $(71 \%)$ and most were born in Switzerland (79\%); $78 \%$ were students or apprentices, $12 \%$ had a full-time job.

Participants' cannabis and alcohol use in the 30 days before the consultation are presented in Table 1. One in seven participants presented excessive cannabis use, and one in three presented excessive alcohol use; $30 \%$ of females and $27 \%$ of males smoked cigarettes at least once a day. Other substance use was rare (two participants reported trying cocaine).

The GPs provided information about the duration of the intervention for $70 / 76$ patients. In most cases (73\%), the intervention lasted 5 minutes or less; for 14 participants (20\%) it lasted between 6 and 10 minutes, and for two patients more than 10 minutes.

Less than half $(42 \%)$ of those who had provided email contact details, and $91 \%$ of those who had provided mobile phone details completed the followup questionnaire. Therefore, follow-up data were available for 48 participants (63\%). 


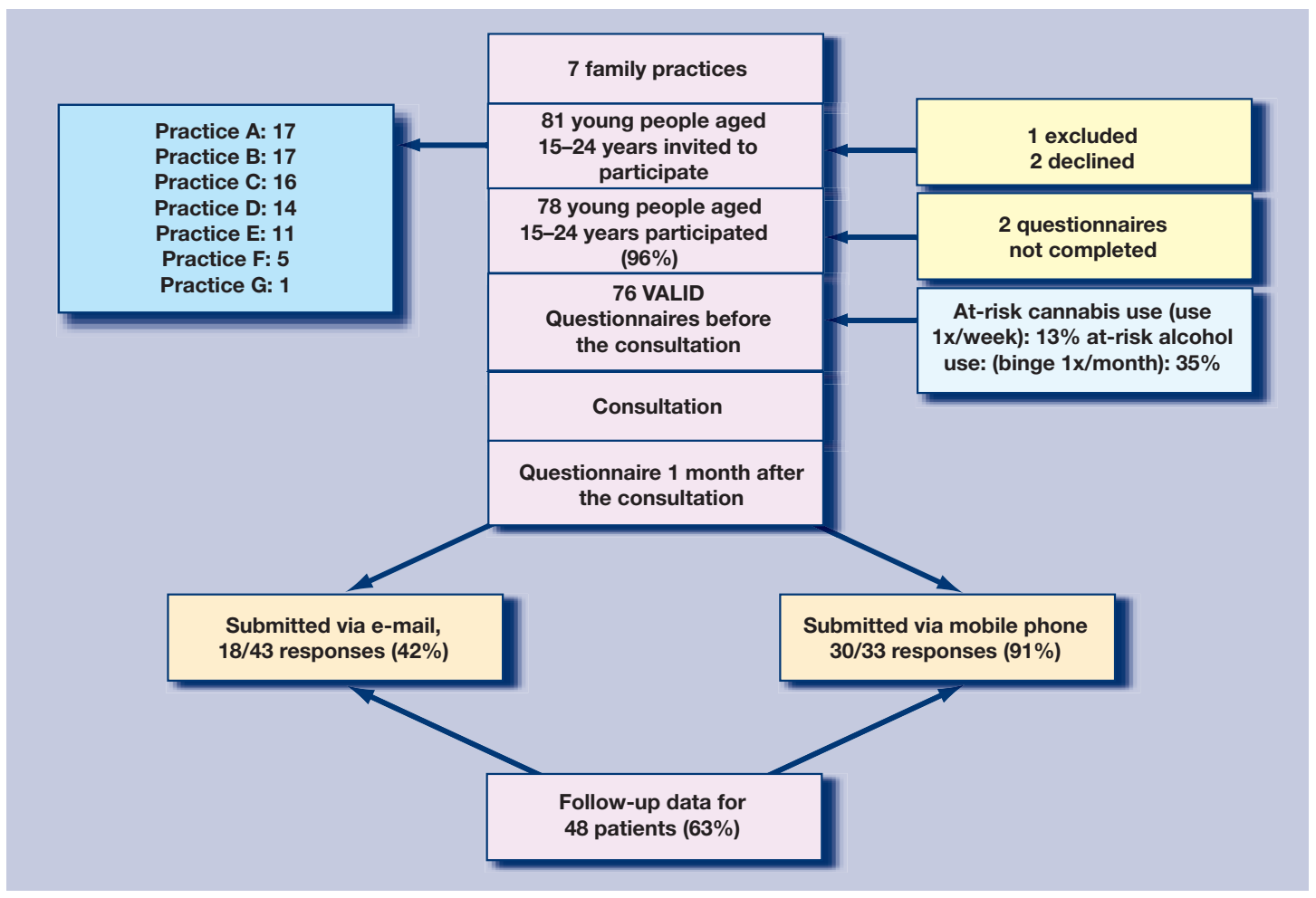

Figure 1. Diagram summarising the pilot study.

\section{Participants' comments on the study process}

The study was well accepted by practice staff and participants. There were no complaints from other patients despite the fact that the study occasionally led to disruptions in the doctor's schedule. The practice staff and the doctors highlighted the need to be flexible in their schedule to compensate for the additional time some patients needed to complete the questionnaire. However, the doctors felt they could easily accommodate elements of the intervention in the normal consultation time. The intervention only led to longer consultations when they felt this could be beneficial to their patient. Overall, the GPs felt the intervention was valuable and useful. One GP reported being unprepared to deal with the discovery of a patient with cannabis dependence and being unsure to whom to refer this patient. When asked to comment on the study at follow-up, the young people were either neutral or positive, and none suggested improvements to be made.

All GPs described personal benefits from participating in the preparatory phase of the study. The literature review on substance use contributed to their continuous medical education. It helped them to discover a neglected reality about young people. The sessions with the actors were valued as a good opportunity to train and improve their communication style with young people. At the end of the study, the GPs felt more at ease discussing cannabis, but also other substance use with young patients. Several GPs reported using the different steps of the intervention to address excessive alcohol use as well. They reported a change in practice and were integrating a discussion of cannabis and other substance use in all their consultations with young patients.

Table 1. Cannabis and alcohol use in the 30 days prior to the consultation.

\begin{tabular}{lcccccccc} 
& \multicolumn{3}{c}{ Cannabis } & & & Alcohol \\
\cline { 2 - 3 } $\begin{array}{l}\text { Use in } 30 \text { days } \\
\text { before consultation }\end{array}$ & $\begin{array}{c}\text { Females }(n=54) \\
\%(95 \% \mathrm{Cl})\end{array}$ & $\begin{array}{c}\text { Males }(n=22) \\
\%(95 \% \mathrm{Cl})\end{array}$ & $\begin{array}{c}\text { Total }(n=76) \\
\%(95 \% \mathrm{Cl})\end{array}$ & & $\begin{array}{c}\text { Females }(n=54) \\
\%(95 \% \mathrm{Cl})\end{array}$ & $\begin{array}{c}\text { Males }(n=22) \\
\%(95 \% \mathrm{Cl})\end{array}$ & $\begin{array}{c}\text { Total }(n=76) \\
\%(95 \% \mathrm{Cl})\end{array}$ \\
\hline Not used & $79.6(66.6$ to 92.7$)$ & $68.2(49.8$ to 86.5$)$ & $76.3(66.1$ to 86.4$)$ & & $31.5(7.5$ to 55.5$)$ & $18.2(0.0$ to 43.4$)$ & $27.6(8.8$ to 46.4$)$ \\
\hline Approximately once & $9.3(0.0$ to 18.6$)$ & $13.6(0.0$ to 34.8$)$ & $10.5(3.0$ to 18.1$)$ & & $31.5(17.0$ to 45.9$)$ & $54.5(21.6$ to 87.4$)$ & $38.2(22.2$ to 54.1$)$ \\
\hline Weekends or $1-2$ times a week & $1.9(0.0$ to 6.4$)$ & $4.5(0.0$ to 17.5$)$ & $2.6(0.0$ to 9.1$)$ & & $27.8(14.2$ to 41.3$)$ & $18.2(0.0$ to 44.1$)$ & $25.0(13.1$ to 36.7$)$ \\
\hline$\geq 3$ times a week & $9.3(1.0$ to 17.5$)$ & $4.5(0.0$ to 17.5$)$ & $7.9(1.3$ to 14.5$)$ & & $9.3(0.0$ to 22.5$)$ & $4.5(0.0$ to 18.2$)$ & $7.9(0.0$ to 18.8$)$ \\
\hline Every day & $0.0(-)$ & $9.1(6.4$ to 24.6$)$ & $2.6(0.0$ to 6.4$)$ & & $0.0(-)$ & $4.5(0.0$ to 16.1$)$ & $1.3(0.0$ to 4.5$)$ \\
\hline Excessive use & $11.1(1.8$ to 20.5$)$ & $18.2(2.9$ to 33.6$)$ & $13.2(7.5$ to 18.8$)$ & $26.9(9.0$ to 44.9$)$ & $54.5(38.7$ to 70.4$)$ & $35.1(23.5$ to 46.8$)$ \\
\hline
\end{tabular}

${ }^{a}$ Defined as use $\geq 1 \times$ a week in the past 30 days and $\geq 1$ binge drinking episode in the past 30 days for alcohol (5 or more alcoholic drinks on one occasion). 


\section{DISCUSSION}

\section{Summary of main findings}

The results of this pilot study indicate that one in seven patients aged 15 to 24 years consulting a GP could potentially benefit from a brief intervention addressing excessive cannabis use. This brief intervention may also be beneficial in addressing excessive alcohol use in this age group, a problem which affected one in three young people attending the practices. These findings confirm that GPs are in contact with many young people who engage in excessive substance use and, thus, have opportunities for preventing harms associated with these health-compromising behaviours. ${ }^{28}$

\section{Strengths and limitations of the study}

Participation rate was high with only two young people declining to participate. This is in line with previous research and suggests young people welcome participation in research that addresses problems that affect them. ${ }^{29,44}$ That the survey was kept confidential and that young people could consent to participation without asking their parents may also have favoured this high participation rate and avoided an unwelcome selection bias. ${ }^{45}$

All the GPs involved in the pilot test worked in urban settings, and all but one worked in single- or two-doctor practices. Thus, the findings from this pilot study may not necessarily be generalised to other practice settings. Indeed there was a slightly higher proportion of female participants than described in previous studies of young people attending primary care (in which about two-thirds of young patients are female). ${ }^{29,46}$ The GPs involved in the study may have had a tendency to see more female patients than is the case in other practices.

Young people's comments about the study were all positive. However, participants were not asked for feedback about the intervention itself, and therefore there is no information on whether they valued it. In order to protect confidential participation, the young people were not asked to provide their home contact details. Only $42 \%$ of those who had provided their email details returned the follow-up questionnaire, in contrast to $91 \%$ of those who completed the questionnaire on the phone. This suggests that phone contact details should be favoured over email to avoid high rates of attrition that could threaten the validity of findings in future studies. As the follow-up rate was modest, and the follow-up period was short it, is not possible to be certain that an observed reduction in prevalence of excessive substance use was truly significant and sustainable. Without a control group it is not possible to be sure it was due to the intervention. The findings, however, are encouraging and provide a good basis for the design of a future randomised trial. 


\section{Comparison with existing literature}

In contrast to previous research, this pilot study was successful in demonstrating the feasibility of testing such an intervention with young people consulting in family practice. ${ }^{32}$ The involvement of GPs and young people in the design of the study contributed to its success by ensuring that the study procedure was adapted to young people and to family practice..$^{47,48}$ The GPs reported benefits from being involved in designing the study, beyond the positive effects on the study itself. The theoretical and practical training about cannabis use and communicating with young people allowed the GPs to become more at ease with substance use issues and with young people. It motivated them to continue their involvement in improving the health of this often-neglected group of patients.

The GPs reported that the intervention did not significantly disrupt the consultation, and that most of the time it could be delivered in no more than 5 minutes. These findings are similar to those of previous research on a brief intervention developed specifically for use in primary care. ${ }^{22}$

\section{Implications for future research}

This brief intervention shows that there is potential in addressing excessive cannabis use among young people consulting in family practice. As the GPs reported using the principles of the intervention additionally to address excessive alcohol use, the intervention also has potential in addressing excessive alcohol use in this age group. The results of this pilot trial will inform the design of a large randomised controlled trial testing the intervention against usual care to confirm that this intervention can indeed lead to positive and sustainable changes in young people's substance use.

\section{Funding body}

This study was funded through a grant from the Swiss Academy of Medical Sciences ('Fonds RRMA'), (RRMA 3/06)

\section{Ethical approval}

The study protocol was approved by the ethics committee of the Geneva Physicians' Association, Switzerland, (Protocol 07-01)

\section{Competing interests}

The authors have stated that there are none

\section{Acknowledgements}

We are grateful to the following GPs for their participation in developing and piloting the study: Drs D Mottu, F le Broccard, R Suzuki, F George, A Michaud, L Regard, D Dupasquier, Y Beyeler, F Maggi, and A Rieder. We thank PA Michaud, JC Suris, LA Sanci, SM Sawyer, GC Patton, and O Ukoumunne for their advice in the initial phase of the study. We also thank the young people who participated in the advisory group, and the four young actors, as well as all the participants in the study for their valuable contribution to this research project.

\section{Discuss this article}

Contribute and read comments about this article on the Discussion Forum: http://www.rcgp.org.uk/bjgp-discuss 


\section{REFERENCES}

1. Hall W, Solowij N. Adverse effects of cannabis. Lancet 1998; 352(9140): 1611-1616.

2. Fergusson DM, Horwood LJ, Swain-Campbell N. Cannabis use and psychosocial adjustment in adolescence and young adulthood. Addiction 2002; 97(9): 1123-1135.

3. Lynskey M, Hall W. The effects of adolescent cannabis use on educational attainment: a review. Addiction 2000; 95(11): 1621-1630.

4. Moore TH, Zammit S, Lingford-Hughes A, et al. Cannabis use and risk of psychotic or affective mental health outcomes: a systematic review. Lancet 2007; 370(9584): 319-328.

5. Patton GC, Coffey C, Carlin JB, et al. Cannabis use and mental health in young people: cohort study. BMJ 2002; 325(7374): 1195-1198.

6. Solowij N, Stephens RS, Roffman RA, et al. Cognitive functioning of longterm heavy cannabis users seeking treatment. JAMA 2002; 287(9): 1123-1131.

7. Taylor DR, Poulton R, Moffitt TE, et al. The respiratory effects of cannabis dependence in young adults. Addiction 2000; 95(11): 1669-1677.

8. Patton GC, Coffey C, Lynskey MT, et al. Trajectories of adolescent alcohol and cannabis use into young adulthood. Addiction 2007; 102(4): 607-615.

9. Coffey C, Carlin JB, Lynskey M, et al. Adolescent precursors of cannabis dependence: findings from the Victorian Adolescent Health Cohort Study. BrJ Psychiatry 2003; 182: 330-336.

10. Narring F, Tschumper A, Inderwildi Bonivento L, et al. SMASH 2002: sante et styles de vie des adolescents agés de 16 à 20 ans en Suisse. [Health and lifestyle of adolescents aged 16 to 20 years in Switzerland]. Lausanne: IUMSP, 2003.

11. Schmid H, Gaume J, Kuntsche EM, et al. Santé et comportements de santé chez les élèves - stades de développement, évolution au cours du temps et comparaisons internationales. [Health and health behaviours in school-aged students - developmental stages, time trends and international comparisons]. Report No. 39. Lausanne: ISPA, 2004.

12. Currie C, Roberts C, Morgan A, et al. Young people's health in context. Health Behaviour in School-aged Children (HBSC) study: international report from the 2001/2002 survey. Copenhagen: WHO Regional Office fo Europe, 2004.

13. Schmid H, Delgrande JM, Kuntsche EN, et al. HBSC: Der Konsum psychoaktiver Substanzen von Schülerinnen und Schülern in der Schweiz Ausgewählte Ergebnisse einer Studie, durchgeführt unter der Schirmherrschaft der Weltgesundheitsorganisation (WHO). [HBSC: The use of psychoactive drugs by school-aged children in Switzerland. Selected results from a study conducted with the support of the World Health Organisation]. Lausanne: SFA-ISPA, 2008.

14. Groupe de Travail Monitoring Cannabis. La consommation de cannabis en suisse et ses conséquences: vue d'ensemble 2004. [Cannabis use in Switzerland and its consequences: overview in 2004]. Berne: OFSP, 2005.

15. Mueller R, Bacher E, Fahrenkrug H, et al. Cannabis, Etat des lieux en Suisse. [Cannabis: overview of the situation in Switzerland]. Lausanne: ISPA, 2004.

16. Office Fédéral de la Santé Publique. Realize it! [Swiss Federal Office of Public Health. Realize it!'] Berne: OFSP, 2004.

17. Office Fédéral de la Santé Publique. Pour un bon développement chez les jeunes. Prévention en faveur d'enfants et adolescent à risque. Recommandations d'une expertise collective. [Swiss Federal Office of Public Health. For a good youth development: prevention for children and adolescents at risk. Recommendations from a group of experts]. Berne: OFSP, 2004.

18. Beich A, Thorsen T, Rollnick S. Screening in brief intervention trials targeting excessive drinkers in general practice: systematic review and meta-analysis. BMJ 2003; 327(7414): 536-542.

19. Bertholet N, Daeppen JB, Wietlisbach V, et al. Reduction of alcohol consumption by brief alcohol intervention in primary care: systematic review and meta-analysis. Arch Intern Med 2005; 165(9): 986-995.

20. Dunn C, Deroo L, Rivara FP. The use of brief interventions adapted from motivational interviewing across behavioral domains: a systematic review. Addiction 2001; 96(12): 1725-1742.

21. Grossberg PM, Brown DD, Fleming MF. Brief physician advice for highrisk drinking among young adults. Ann Fam Med 2004; 2(5): 474-480.

22. Ruff P, Regenass E, Ott R. Raucherberatung [minimal intervention] in der Hausarztpraxis-NicoLei — ein Motivationsprojekt des Aerztevereins Leimental zum Nicotinstop. [Counselling smokers (minimal intervention) in the family practice. NicoLei: a motivational project of the medical association of Leimental to favour nicotine stop]. Prim Care 2006; 6(7-8): 150-155.

23. Loxley W, Toumbourou JW, Stockwell T, et al. The prevention of substance use, risk and harm in Australia. Canberra: The National Drug Research
Centre and the Centre for Adolescent Health, 2004.

24. Lubman DI, Hides L, Yucel M, Toumbourou JW. Intervening early to reduce developmentally harmful substance use among youth populations. Med J Aust 2007; 187 (7 suppl): S22-S25.

25. Jeannin A, Narring F, Tschumper A, et al. Self-reported health needs and use of primary health care services by adolescents enrolled in postmandatory schools or vocational training programmes in Switzerland. Swiss Med Wkly 2005; 135(1-2): 11-18.

26. Choquet M, Ledoux S. Adolescents: enquete nationale. Analyses et prospective. [Adolescents: national survey. Analysis and perspectives]. Paris: INSERM, 1994.

27. Zimmer-Gembeck MJ, Alexander T, Nystrom RJ. Adolescents report their need for and use of health care services. J Adolesc Health 1997; 21(6): $388-399$.

28. Haller DM, Michaud PA, Suris JC, et al. Opportunities for prevention in primary care in a country with universal insurance coverage. J Adolesc Health 2008; 43(5): 517-519.

29. Haller DM, Sanci LA, Patton GC, Sawyer SM. Toward youth friendly services: a survey of young people in primary care. J Gen Intern Med 2007; 22(6): 775-781.

30. Sanci L, Haller D, Vance A, et al. Common mental health problems in adolescence. In: Blashki G, Judd F, Piterman L (eds). General practice psychiatry. North Ryde, NSW: Mc Graw-Hill, 2007; 231-256.

31. McCambridge J, Strang J. The efficacy of single-session motivational interviewing in reducing drug consumption and perceptions of drugrelated risk and harm among young people: results from a multi-site cluster randomized trial. Addiction 2004; 99(1): 39-52.

32. Knight JR, Sherritt L, Van Hook S, et al. Motivational interviewing for adolescent substance use: a pilot study. J Adolesc Health 2005; 37(2): $167-169$.

33. Loxley WM, Toumbourou JW, Stockwell TR. A new integrated vision of how to prevent harmful drug use. Med J Aust 2005; 182(2): 54-55.

34. Marlow SP, Stoller JK. Smoking cessation. Respir Care 2003; 48(12): 1238-1254; discussion 54-56

35. Miller WR, Rollnick S. Motivational interviewing: preparing people for change. New York: Guilford Press, 2002

36. Sanci L, Glover S, Coffey C. Adolescent health education programmes theoretical principles in design and delivery. Ann Acad Med Singapore 2003; 32(1): 78-85

37. Tylee A, Haller DM, Graham T, et al. Youth-friendly primary-care services: how are we doing and what more needs to be done? Lancet 2007 369(9572): 1565-1573.

38. World Health Organization. Young people's health — a challenge for society: report of a WHO Study Group on Young People and 'Health for All by the Year 2000'. Geneva: WHO, 1986.

39. Sanci LA, Sawyer SM, Kang MS, et al. Confidential health care for adolescents: reconciling clinical evidence with family values. Med J Aust 2005; 183(8): 410-414.

40. Haller DM, Sanci LA, Patton GC, Sawyer SM. Practical evidence in favou of mature-minor consent in primary care research. Med J Aust 2005; 183(8): 439

41. Sanci LA, Sawyer SM, Weller PJ, et al. Youth health research ethics: time for a mature-minor clause? Med J Aust 2004; 180(7): 336-338.

42. Germain M, Guyon L, Landry M, et al. DEP-ADO: Grille de dépistage de consommation problématique d'alcool et de drogues chez les adolescents et les adolescentes. [DEP-ADO: A tool to screen for problematic alcohol and drug use in adolescents.] Version 3.1. Montréal: Recherche et intervention sur les substances psychoactives — Québec (RISQ), 2005.

43. Brodey BB, McMullin D, Winters KC, et al. Adolescent substance use assessment in a primary care setting. Am J Drug Alcohol Abuse 2007; 33(3): 447-454.

44. McKelvey RS, Pfaff JJ, Acres JG. The relationship between chief complaints, psychological distress, and suicidal ideation in 15-24-year-old patients presenting to general practitioners. Med J Aust 2001; 175(10): 550-552.

45. Rojas NL, Sherrit L, Harris S, Knight JR. The role of parental consent in adolescent substance use research. J Adolesc Health 2008; 42(2): 192-197.

46. Ozer EM, Adams SH, Lustig JL, et al. Increasing the screening and counselling of adolescents for risky health behaviours: a primary care intervention. Pediatrics 2005; 115(4): 960-968.

47. Del Mar C, Askew D. Building family/general practice research capacity. Ann Fam Med 2004; 2(suppl 2): S35-S40.

48. Society for Adolescent Medicine. Guidelines for adolescent health research. A position paper of the Society for Adolescent Medicine. $J$ Adolesc Health 2003; 33: 396-409. 